\title{
REINVENTING UNIVERSITIES: AGILE PROJECT MANAGEMENT IN HIGHER EDUCATION
}

\author{
Pavle Ivetić ${ }^{1}$, Jovana Ilić ${ }^{2}$
}

\begin{abstract}
${ }^{1}$ University of Belgrade, Faculty of Organizational Sciences, Belgrade, Serbia

${ }^{2}$ University of Belgrade, Faculty of Philology, Belgrade, Serbia
\end{abstract}

Received: 10 May 2020

Revised: 15 June 2020

Accepted: 27 July 2020

\begin{abstract}
Universities worldwide are facing similar problems, decrease in public funding, increase of international competition and slow bureaucratic organization. One of the possibilities to increase flexibility and to respond better to students' needs and job market changes is implementing Agile Project Management practices. Both Agile and its most popular Scrum methodology have origins in Software development but have been successfully adopted in other industries as well. This paper examined specific Agile Project Management practices that can be implemented in different areas of Universities, such as Governance and Structure, Curriculum Design, Teaching, Learning, Evaluation, Online Courses and Virtual Classroom. It is concluded that Universities could foster benefits by implementing Agile practices partly, incrementally or by having a full Agile transformation, but either way a goodwill to test it and internal champions to lead the change represent crucial elements of such transformation.
\end{abstract}

Keywords: Agile project management, universities, scrum, transformation, higher education.

\section{INTRODUCTION}

Having in mind changes in public funding the universities are facing worldwide, Researchers have argued that universities need to increase their flexibility and do things cheaper, easier, and faster (Prange \& Chen, 2016). In recent years, researchers are showing an increased interest in the inevitable changes the universities are facing globally, turning towards exploring how those should be managed and predicting what course the worldwide academic community will take in the future. Universities need to change so they can respond better to the needs of both students and the market.

When analyzing Information Technology (IT) industry and how it is successfully coping with everlasting daily changes, most common denominator in the last 20 years is Agile methodology. Agile methodology and its most popular framework Scrum have been on the rise year by year, starting from the end of the $\mathrm{XX}$ century and still growing. Agile advocates incremental development, short time to market cycles, responding to feedback quickly and adopting to deliver the highest value to stakeholders and clients (Agilemanifesto, 2001).

As noted by Eschenbach et all (Eschenbach, 2015) professors' work can be observed as collection of projects (teaching, performing research, writing scientific papers, preparing course materials, etc.) with flexible scope and some more fixed constraints as cost and time available. When making a comparison with IT projects, projects with flexible scope are better handled with Agile than traditional Project Management techniques, but in higher education, they are almost exclusively handled with traditional Project Management.

Corresponding author. Email: pavle.ivetic@ rect.bg.ac.rs

ISSN 2560-4961 (online)

Copyright (C) 2020, The Authors. Published by IPMA Serbia.

This is an open access article under the CC BY-NC 4.0 license (https://creativecommons.org/licenses/by$\mathrm{nc} / 4.0 /$ )

doi: $10.18485 /$ epmj.2020.10.1.7 
Can universities really become Agile, or at least foster some of the benefits by adopting some of Agile techniques, frameworks and good practices because of which Agile become so popular and effective? This paper will analyze current options and possibilities. The rest of the paper is organized as follows: after Introduction, the Section 2 gives a brief overview of Agile, its values, principles and its most popular techniques. Section 3 presents how different Agile practices can be applied in universities within different areas. Finally, Section 4 concludes this paper.

\section{AGILE PROJECT MANAGEMENT OVERVIEW}

The term Agile was first started using during 1990s but became popular when 17 software developers wrote and published the Agile Manifesto in 2001 (Agilemanifesto, 2001). Agile Manifesto defined 4 values and 12 principles, and they were a foundation for the Agile Software Development and Agile Project Management, both relying on incremental progress, which encompass short feedback, loops. Agile values are not strict rules but more like flexible guidelines that prefer one thing to another, depending on the specific context.

Agile methodology is known for its non-rigid and non-linear trajectory in project management, consisted of short cycles in managing and executing smaller project units and delivering results. The methodology is designed in such a way to give an option for the next step to be decided about along the way, in accordance with what has been recognized as best for the further project development at the moment, allowing for additional changes and adjustments to be implemented as needed.

Self-organizing and shared responsibility are often mentioned as key management practices for Agile. Self-organizing teams can bring a lot of positive effects for the organizations, but fostering all the benefits and avoiding possible pitfalls is a challenge (Ivetic, 2017).

Most popular and widely known Agile methodology is Scrum which is used more often than all other Agile methodologies combined together (The 13th annual State of
Agile Report, 2019). Scrum is defined as "framework within which people can address complex adaptive problems, while productively and creatively delivering products of the highest possible value" (Schwaber, \& Sutherland, 2017). Main characteristics of Scrum are: self-organizing cross-functional teams which are working in iterations called Sprints. Sprints are ranging from one to four weeks usually and are comprised of 4 import events: 1. Sprint Planning (at the beginning of a Sprint), 2. Daily Stand-up (daily follow-up), 3. Sprint Review (presentations held during the last days of a Sprint), 4. Sprint Retrospective (a team review of a completed Sprint). Scrum also defines members of a Scrum Team: Product Owner, the Development Team, and a Scrum Master (Schwaber, \& Sutherland, 2017). The Product owner prioritize the work for the team and he is a link between the Scrum team and the outside world. Development Team is a self-organizing and cross-functional team, usually of 5-7 people who can deliver some work at the end of each Sprint. Scrum Master is in charge of facilitating all Scrum events and should not be mistaken for a Manager. When compared with Agile, Scrum is stricter with well-defined roles and processes while Agile relies upon values and loose guidelines which can be adopted in many different ways.

\section{AGILE UNIVERSITIES}

At first glance, what Agile offers may not seem as appealing and safe as traditional approaches. No sit-back in safeness of prescribed procedures or a copy-paste of tested and proven practices, no responsibility shifting. Instead, Agile asks for a continuous engagement, exploration, observation, feedback and adjustment.

The best of the results will come through numerous iterations and fine-tuning, and by getting to know more and more details of a particular context. With ever changing market needs, universities need to keep pace with the changes and adopt accordingly. What follows is what the authors of the paper have identified as the key different segments of possible implementation of the Agile practices within a university environment. 
Governance and structure. What academic environment could take from Agile and it's good practice in software development is replacing the traditional, rigid and hierarchical relationship with a collaborative partnership, based on continuous feedback and exchange where each position (of a student or a teacher) has equally to offer and is always required to reinvent itself and to adjust to each new reality reached by successful fulfillment of a previously set and mutually agreed upon task, while both taking individual responsibility and collaborating in the same time. The learning process for students would change as well as they would learn less from purely obeying instructions, and more from their first-hand experience of trial and error as well as from taking a responsibility of designing and testing the learning process and of its results.

Curriculum design. It could be said that there is a paradox in high demand for university degrees of all levels on one side (something that could be individually observed and maybe looked through the prism of a global financial crisis) and the wellknown fact that the degree is no longer a guarantee neither for an employment nor, ironically, for being sufficiently trained and prepared for the requirements of the real market. Furthermore, many young people see studying as a risky investment and a possible waste of precious time in their late teens/early twenties. A student can pass 40 out of 41 exams as part of a bachelor degree, spent 3, 4 or more years doing it, but without that last exams he or she is considered as dropout and valued as the ones who did not even enrolled at the university. Therefore, many young people chose to turn to an independent or online education in learning skills, mostly in a broader IT context, to start up their own businesses, focusing on product, impact and commercial gain. With applicable and updated knowledge and skills, within the IT sector especially, they are often not even asked about their academic qualifications. Instead of exclusively offering degrees that take from one to two years (Master degrees) to up to several years (Bachelor and Doctoral studies), universities can introduce shorter degrees of less than one year to up to a year. This way for example, a 3-year Bachelor degree can consist of 6 smaller sub-degrees, each lasting 66 one semester and most importantly - each with a specific learning outcome. Each subdegree could be thematized with related courses within it. These new sub-degrees could also be offered separately, outside degree seeking, for people within the industry who wants to update or refresh their knowledge, or for the people who are just interested in specific thematic, or to job seekers who see them as valuable in their quest for getting a better job. Some variations already exist and they are called nanodegrees, developed by the industry and Massive Open Online Courses (MOOC) providers, usually without the involvement of universities (Lemoine, \& Richardson, 2015), but certainly this is a field for further exploration and testing.

Teaching and learning. Inside the classroom there are several modifications of Scrum and Agile principles in general which are already successfully adopted. Most widely known modification of Scrum for teaching and learning is called eduScrum. The eduScrum translates the Scrum process, roles and responsibilities in pedagogic terms, that can potentially be applied to teach any subject at any education level (Delhij, van Solingen, \& Wijnands, 2015). Similar variation is also described by Royle and Nikolic (Royle, \& Nikolic, 2016), who pointed out the freedom given to teams to make their own decisions and assign tasks to themselves within short time unites, with a possibility to check the work and change and adjust the process if needed.

Online courses and virtual classroom. Internet and the digital revolution have not bypassed the area of higher education. First university in the United Kingdom that offered online courses exclusively, and currently the largest university in the country with over 200,000 students, the Open University, relies heavily on Agile practices. This helped them to respond faster to market needs and feedback from students, so now they "produce nearly 200 new online courses and update 300 more every year" (Linders, no date). In addition, the Open University is the largest provider of higher education for people with disabilities (Facts and figures | About The Open University, no date). When analyzing an online educational environment, Catheryn 
Cheal (Cheal, no date) insists on student feedback being a crucial part of a course design and compares the originally designed online courses with nowadays predominating tendencies, seeing them as less resembling to traditional classroom models. Instead, the second-generation online courses as Cheal names it, depend "upon competency-based and problem-based learning and self-paced, individualized online modules". Short videos, quiz questions, self-paced and personalized modules, real-life content and case studies, the sense of engagement, peer-to-peer interaction and real-time tutoring are the positive features of such approach according to the author. However, Cheal draws attention that the most appealing possibilities the new generation of online courses offers could be the competency-based software as well as the automated grading that would enable massive enrollments, unlike the previous manual grading that was time consuming.

Evaluation. If the course content would be arranged through previously discussed smaller chunks, the expected learning outcomes could be evaluated more frequently at each milestone throughout the semester, instead of having one bulky and stressful semestral examination. This would be less stressful and would keep students continuously engaged and focused within the specific topic. It would also help them in connecting the previous knowledge into a coherent whole and building steady and applicable understanding of the specific topic. A milestone for an evaluation can be set after several lectures, where each lecture could contain a brief knowledge check of the content taught at the previous one. As mentioned previously, an Agile approach to project management is based on processing smaller chunks in shorter time units, with a continuous feedback and with an opportunity to change and adjust the route along the way as new circumstances and observations arise.

\section{CONCLUSION}

Teaching practice at universities is often forced to follow administrative procedures, official curricula and final tests and exams as an ultimate measure of the learning outcome. Regardless of their traditionally traditional approaches, the universities should not stick to the old ways, but create new ways instead, move boundaries of human evolution and help their students succeed in the game of life. Universities and everyone they employ should exist because of the students, not the other way around. Can Agile be successfully applied among the same people who have been working their whole lives with a bureaucratic mindset and in bureaucratic environments? Maybe yes, maybe not, it depends. It needs to be tested out. But before it's tested out, there must be a (good) will to even consider it. Even if making an entire institutional organization pro-Agile sounds undoable or simply too-much, there are many aspects in the practices and services of a university where Agile could be easily implemented, incrementally.

It is no surprise that innovation such as Agile is usually carried out by the minority, often enthusiastic and courageous individuals who have seen beyond generally accepted practices and have understood how beneficial it can be be it in a graphic design studio or an IT startup on the one side, or in a traditional institution such as universities are. As said before, implementing Agile does not mean allowing for chaos and anarchy. It actually increases individual responsibility and discipline and promotes the system where procedures and processes cannot exist as an end in itself but serve the purpose of attaining results and fulfilling objectives, never letting out of sight the reality and the needs of the present moment. If changes and adjustments are needed - an agile mindset will not be stuck in the reality of yesterday. It will act immediately, working with the new inputs and new circumstances, responsibly and with a focus on the final objective and desired results.

\section{REFERENCES}

Agilemanifesto. (2001). Manifesto for Agile Software Development. Available at: http://agilemanifesto.org/ (Accessed: 20 July 2019).

Cheal, C. (no date). Five Central Characteristics of Agile Universities | The EvoLLLution. Available at: https://evolllution.com/opinions/centralcharacteristics-agile-universities/

(Accessed: 2 June 2019). 
Delhij, A., van Solingen, R., \& Wijnands, W. (2015). The eduScrum Guide: The rules of the Game. Available at: http://eduscrum.nl/en/file/CKFiles/The_e duScrum_Guide_EN_1.2.pdf.

Eschenbach, T. (2015). Using Agile Project Management to Maximize Your and Your Coauthors' Productivity. 2015 ASEE Annual Conference \& Exposition, Seattle, Washington. doi: 10.18260/p.24990.

Facts and figures | About The Open University. (no date). Available at: http://www.open.ac.uk/about/main/strate gy-and-policies/facts-and-figures (Accessed: 25 May 2019).

Ivetic, P. (2017). Holding the house of cards together: Possible pitfalls with selforganizing teams in organizations, Econophysics, Sociophysics \& Other Multidisciplinary Sciences Journal (ESMSJ). VII(2), pp. 51-57. Available at: https://www.researchgate.net/profile/Pavl e_Ivetic/publication/322526048_Holding _the_House_of_Cards_Together_Possibl e_Pitfalls_with_Self-

Organizing_Teams_in_Organizations/lin ks/5a5e03b6aca272d4a3dfa3a1/Holdingthe-House-of-Cards-Together-PossiblePitfalls-.

Lemoine, P. A., \& Richardson, M. D. (2015). Micro-Credentials, Nano Degrees, and Digital Badges. International Journal of
Technology and Educational Marketing. 5(1), pp. 36-49. doi: 10.4018/ijtem.2015010104.

Linders, B. (no date). Agile in Higher Education: Experiences from The Open University. Available at: https://www.infoq.com/news/2019/03/agi le-higher-education (Accessed: 18 May 2019).

Prange, C., \& Chen, S. (2016). Agile Universities - Transforming the Future of Teaching and Learning. SMS Special Conference on Contextualizing Strategic Management in Asia: Institutions, Innovation and Internationalization, pp. $1-7$.

Royle, K., \& Nikolic, J. (2016). A modern mixture, Agency, Capability, Technology and "Scrum": Agile Work Practices for Learning and Teaching in Schools, Journal of Education \& Social Policy. 3(3), pp. 37-47.

Schwaber, K., \& Sutherland, J. (2017). The Scrum Guide. doi: 10.1053/j.jrn.2009.08.012.

The 13th annual State of Agile Report (2019). Available at: www.stateofagile.com.

Zack, T. (no date). The BDasics of Agile Transformation. Available at: https://www.leadingagile.com/2018/07/th e-basics-of-agile-transformation/ (Accessed: 22 September 2019). 